\title{
DÜBLIN
}

Technological University Dublin

ARROW@TU Dublin

Articles

2020-3

\section{The relationship between serum zinc levels and myopia}

\author{
Niamh Burke \\ Technological University Dublin \\ John Butler \\ TU Dublin, john.s.butler@tudublin.ie \\ Daniel I. Flitcroft \\ Technological University Dublin
}

See next page for additional authors

Follow this and additional works at: https://arrow.tudublin.ie/otpomart

Part of the Optometry Commons

\section{Recommended Citation}

Burke, N. et al (2020) The relationship between serum zinc levels and myopia. Clin Exp Optom. (2020) doi:10.1111/cxo.13069

This Article is brought to you for free and open access by ARROW@TU Dublin. It has been accepted for inclusion in Articles by an authorized administrator of ARROW@TU

Dublin. For more information, please contact arrow.admin@tudublin.ie, aisling.coyne@tudublin.ie, gerard.connolly@tudublin.ie.

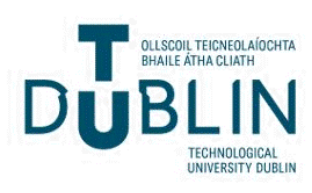




\section{Authors}

Niamh Burke, John Butler, Daniel I. Flitcroft, and James Loughman

This article is available at ARROW@TU Dublin: https://arrow.tudublin.ie/otpomart/81 


\section{AUTHOR QUERY FORM}

Dear Author,

During the preparation of your manuscript for publication, the questions listed below have arisen. Please attend to these matters and return this form with your proof.

Many thanks for your assistance.

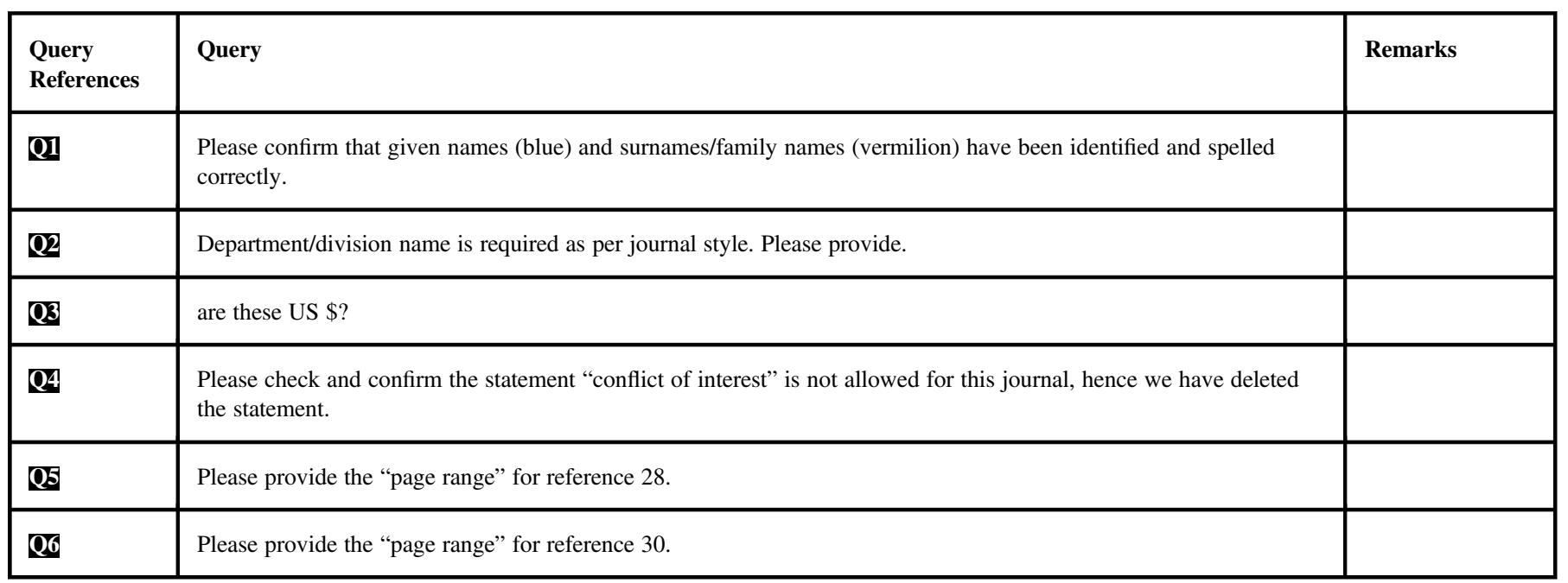




\section{RESEARCH \\ The relationship between serum zinc levels and myopia}

Clin Exp Optom 2020

DOI:10.1111/cxo.13069

Niamh Burke* MSc

John S Butler* ${ }^{\dagger} \mathrm{PhD}$

Ian Flitcroft ${ }^{*}$ FRCOphth

James Loughman* PhD

*Centre for Eye Research Ireland, School of Physics, Clinical \& Optometric Sciences, College of Sciences \& Health, Technological University Dublin, Dublin, Ireland

${ }^{\dagger}$ School of Mathematical Sciences, College of Sciences \& Health, Technological University Dublin, Dublin, Ireland

${ }^{\ddagger}$ Temple Street Children's University Hospital, Dublin, Ireland

E-mail: nia_burke@yahoo.com

Submitted: 24 November 2019

Revised: 4 March 2020

Accepted for publication: 11 March 2020
Clinical significance: Myopia is inherently associated with eye growth and thereby possibly amenable to nutritional influence. However, little attention has been given to possible dietary influences. This study demonstrates that serum zinc does not play a role in myopia development.

Background: Myopia is inherently associated with eye growth and thereby possibly amenable to nutritional influence. A number of Asian studies have reported lower levels of serum zinc in myopic children. This study was designed to assess the relationship between serum zinc and myopia in the Korean population - using a subsample of participants from nationally representative data.

Methods: Data from the fifth Korean National Health and Examination Survey (KNHANES) 2010 were used to explore zinc status in relation to refraction. A total of 304 participants were analysed, ranging in age from 12 to 19 years. Serum zinc levels were measured using inductively coupled plasma mass spectrometry, while refractive error was determined by non-cycloplegic autorefraction. Multivariate analysis was used to examine the association.

Results: A significant majority of participants ( $n=255$; 84 per cent) were myopic. There was no significant difference in serum zinc levels between myopic and non-myopic children $(p=0.81)$. In multivariate logistic regression, serum zinc was not significantly associated with myopia after adjustment for age, gender, residence, body mass index, family income and recreational activity. Similarly, no relationship was observed between spherical equivalent refraction and serum zinc within the myopic group $(p=0.46)$.

Conclusion: In a subset of 12-19-year-old participants from the population-representative KNHANES study, no association was found between serum zinc and myopia. However, the lack of a sensitive biomarker for zinc status remains a major limitation in this, and all current studies.

Key words: KNHANES, myopia, refractive error, serum zinc

The prevalence of myopia has risen dramatically over recent decades, with no evidence of slowing. ${ }^{1}$ Myopia levels of $80-90$ per cent have been reported in school leavers in countries like Singapore, South Korea, China, and other high-income areas of East and South East Asia. ${ }^{1}$ In fact, a study carried out in Seoul, South Korea, in 2010, found the prevalence of myopia to be 96.5 per cent in 19-year-old males. ${ }^{2}$ These rising levels have serious public health implications, creating a range of detrimental health and socio-economic impacts. Health impacts arise where optical correction to alleviate the symptoms of myopia is unavailable and because of the range of ocular comorbidities associated with myopia. ${ }^{3}$ Socioeconomic impacts include lost productivity associated with vision loss, the direct and indirect costs of treating myopia and its ocular comorbidities, costs associated with vision impairment and blindness along with any resultant quality of life effects. The global productivity lost due to uncorrected myopia, for example, is estimated to be a massive $\$ 244$ billion annually, with an additional $\$ 6$ billion loss due to just one of the complications associated with myopia, myopic macular degeneration. ${ }^{4}$ In Singapore alone, the annual direct cost of optical correction of myopia for adults has been estimated at US\$755 million. ${ }^{4}$

Genetic factors are thought to play a role in myopia development or susceptibility to myopia, but it is clear that genetic change is too slow to account for these accelerated rates. ${ }^{5}$ It is therefore now widely accepted that environmental influences play a large role. Environmental factors have influenced and changed many aspects of our modern lifestyle - increasing urbanisation, for example, is a generally accepted risk factor for myopia, which may relate, at least in part, to behavioural aspects of urban living. ${ }^{6,7}$ Currently, there is a need for exploration and investigation into other potential environmental or lifestyle-based driving forces in this myopia pandemic.

Little attention has been given to possible dietary influences, which is somewhat surprising as myopia is inherently associated with ocular growth and diet has been identified as a factor in many other ocular diseases such as age-related macular degeneration, cataract and diabetic retinopathy. ${ }^{8,9}$ The Singapore Cohort Study of Risk Factors for Myopia (SCORM) performed a dietary analysis on 851 Chinese children through a food frequency questionnaire, and found that saturated fat and cholesterol 
intake may be associated with axial elongation in otherwise healthy Singapore Chinese schoolchildren, ${ }^{10}$ but no association was found between any specific nutrient and myopia development. Older studies, which examined the diet of myopes, have yielded inconsistent findings, perhaps reflecting study limitations including inadequate dietary data collection methods and small samples sizes. ${ }^{11,12}$

More recently, a small number of Asian studies have reported lower levels of micronutrients such as zinc and copper in myopic children/adolescents, when compared to controls. A study which examined trace elements in hair samples of 100 college students aged 20-24 found zinc levels were inversely associated with degree of myopia. ${ }^{13}$ Similar findings were noted in three other Chinese observational studies, suggesting that lower zinc levels merit consideration as a possible factor in the development and/or progression of myopia. ${ }^{14-16}$

The use of a large nationally representative population-based source of zinc status and refraction data to investigate the possible relationship between zinc and myopia would provide an important advance on existing studies. The Korean National Health and Nutrition Examination Survey (KNHANES) represents an ideal source of such data. The Korean diet, which is predominantly comprised of rice, vegetables, fish and fermented vegetables, is very different from the Western diet, where high sugar, high fat and overly processed foods make-up a substantially larger proportion of the diet. ${ }^{17}$ While the Korean diet carries many health benefits, and Korea is known to have some of the lowest rates of childhood obesity, ${ }^{18}$ bioavailability of some micronutrients can be low, zinc in particular, due to high intakes of phytates (a known inhibitor to zinc absorption) from rice and vegetables. $^{19,20}$

Zinc is particularly highly concentrated in retinal and choroidal tissue and is involved in various pathways which could be relevant to myopia development and progression including vitamin A metabolism, ${ }^{21}$ transcriptional processes and gene expression. ${ }^{22,23}$ Many genes identified for their role in myopia development contain an all-important zinc finger (ZMAT4, ZIC2, ZBTB38), ${ }^{24}$ while novel mutations found in ZN644, which encodes zinc finger transcription factors, and gene SCL39A5 (zinc transporter) have been associated with early-onset nonsyndromic high myopia. ${ }^{25}$ The aim of this study, therefore, was to assess the association between serum zinc and myopia in the Korean population - using a subsample of adolescents from the KNHANES 2010 study.

\section{Methods}

\section{Study population}

This study is based on data obtained from the first round of the fifth KNHANES 2010 survey (KNHANES V-1). The KNHANES is a nationwide population-based cross-sectional survey; it was conducted on a triennial basis from 1998 to 2005, and in 2007 became an annual survey program. The survey is performed by the Division of Chronic Disease Surveillance, Korea Centres for Disease Control and Prevention. It is carried out to determine public health status and to provide baseline data for the evaluation and improvement of public health policies in the Korean population. Data collected from the KNHANES V-1 conducted from January to December 2010 were used in this study, as this was the last cycle to concurrently assess zinc levels in serum and refractive status.

Participants included non-institutionalised individuals, aged one year and over, living in Korea, and were selected using a stratified, multi-stage cluster probability sampling design to guarantee an independent and comparable sampling each year, as well as nationally representative sampling. Data were collected by a variety of means. Health interviews and examinations were performed in mobile examination centres. $^{26}$ Vision examination was carried out in those aged five or more years. Blood samples were collected from participants $11+$ years; however, heavy metals were only measure in $1 / 3$ of those participants. The Institutional Review Board of the Korean Centres for Disease Control approved all the protocols and the participants provided written informed consent at baseline. KNHANES $\vee$ study design followed the tenets of the Declaration of Helsinki. Additional details regarding the study design and methods is provided elsewhere. ${ }^{27}$

\section{Participant data and measurement}

Demographic variables, including age, gender, area of residence and parental income were collected at household interviews. Area of residence was categorised as urban or rural. Among the 16 districts of South Korea, eight major cities (Seoul, Gyeonggi, Busan, Daegu, Incheon, Gwangju, Daejeoun, and Ulsan) were grouped as urban areas, and the other provinces (Gangwon, Chungbuk, Chungnam, Jeonbuk, Jeonnam, Gyeongbuk, Gyeongnam, and Jeju) were grouped as rural areas. Parental income was divided into quartiles and participants were placed in the low-income group if their parental income fell in the lowest quartile.

A trained examiner completed all anthropometric assessments. Height was measured to the nearest $0.1 \mathrm{~cm}$ using a portable stadiometer (SECA 225; SECA Deutschland, Hamburg, Germany) while the participants were standing barefoot. Weight was measured to the nearest $0.1 \mathrm{~kg}$ using an electronic scale (GL-6000-20; CAS KOREA, Seoul, Korea) while the participants wore a lightweight gown. Body mass index (BMI) was determined by dividing weight in kilograms by height in metres squared $\left(\mathrm{kg} / \mathrm{m}^{2}\right)$. Waist circumference was measured after normal expiration to the nearest $0.1 \mathrm{~cm}$ using a measuring tape (SECA 200; SECA Deutschland). ${ }^{28}$

Recreational activity was established by self-reporting using the International Physical Activity Questionnaire. ${ }^{29}$ Moderate physical activity was categorised as 'yes' when participants engaged in moderate-intensity physical activity for more than 20 minutes at a time and more than three times per week. Moderate-intensity physical activity was defined as the physical activity that causes a slight increase in breathing or heart rate for at least 10 minutes, such as when carrying light loads, cycling at a regular pace, or playing tennis. ${ }^{29}$

Ophthalmic examinations were conducted in mobile examination centres. Noncycloplegic auto refraction was performed three times in both eyes on all participants, using a picture target with the standard background illumination of the Topcon KR8800 auto refractor (Topcon, Tokyo, Japan). The average refraction measurements were separately recorded for each eye. In line with standards, tests were performed by epidemiological survey members of the Korean Ophthalmologic Society, spherical equivalent (SE) refractive error was calculated as sphere and half of the cylinder value. Myopia was defined by a SE of -0.50 dioptres (D) or more. Refractive error was defined based on the right eye.

\section{Laboratory measurements}

Participants were asked to provide overnight fasting blood samples. To measure serum zinc concentrations, a trace element 
tube was used and serum zinc concentration was determined by inductively coupled plasma - mass spectrometry (ICP-MS) using a PerkinElmer mass spectrometer (PerkinElmer, Waltham, MA, USA). Serum samples were diluted with two per cent nitric acid, and serum zinc concentration was obtained from a linear relationship $(r=0.999)$ between concentrations of zinc stock standard $(1,000 \mathrm{mg} / \mathrm{ml}$, SPEX CertiPrep, Metuchen, NJ, USA) and absorbance. The accuracy of the analytical procedures was verified with standard reference material (ClinChek Serum Controls, lyophilised for trace elements, RECIPE, Munich, Germany). The standard deviation index was 0.50 , and coefficients of variation for inter-and intra-assay were two per cent, and four per cent, respectively. ${ }^{30}$

\section{Statistical analysis}

Statistical analysis was performed using SAS survey procedure (version 9.2; SAS Institute

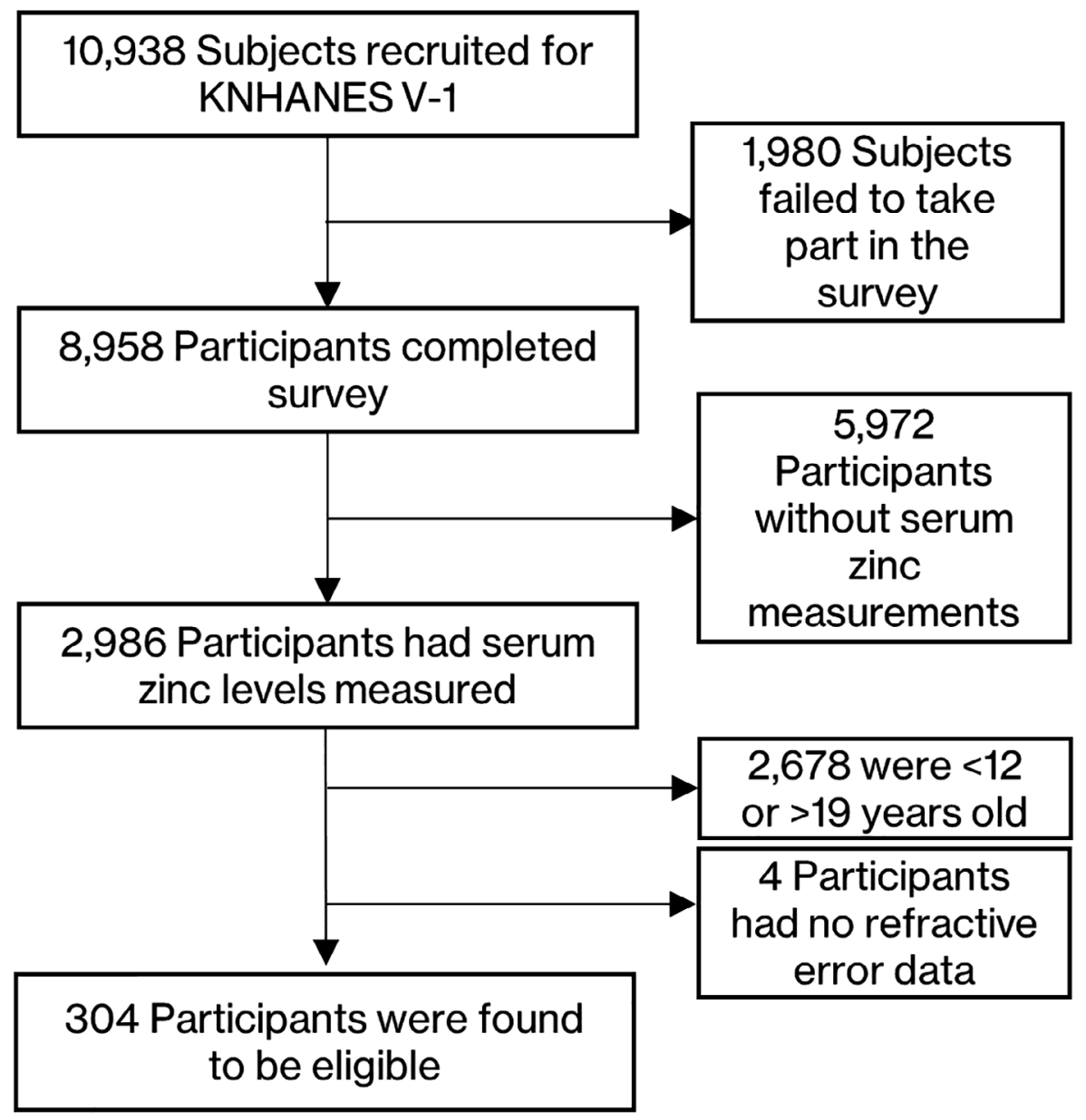

Figure 1. Flow diagram of selection process.
Inc., Cary, NC, USA) to reflect the complex sampling design and sampling weights of KNHANES and to provide nationally representative prevalence estimates. The procedures included unequal probabilities of selection, oversampling, and nonresponse so that conclusions could be made about the Korean adolescent participants. Participants' characteristics were described using mean and standard error for continuous variables and number and percentages for categorical variables. T-tests and Chi-square tests were used for analysis of continuous and categorical variables, respectively. Serum zinc was categorised based on quartiles (quartile $1:<25$ th percentile, quartile 2 : $\geq 25$ to 50th percentile, quartile $3: \geq 50$ to 75th percentile, quartile 4 : $>75$ th percentile). Simple and multiple logistic regression were performed to test the association between serum zinc and myopia, with quartile 1 as the reference category. Model 1 was adjusted for age and gender, while

model 2 was adjusted for age, gender, residence, BMI, family income and recreational activity. To further explore the relationship between total zinc intake and myopia, multivariate linear regression was performed on the association between serum zinc level and $\mathrm{SE}$, in the myopic population. All reported probabilities were two-sided, with $p<0.05$ considered statistically significant.

\section{Results}

In the KNHANES V-1, 10,938 participants were recruited, 8,958 completed the survey (participation rate: 81.9 per cent). Among those, 2,986 had serum zinc levels measured. To specifically target those most at risk of myopia development and progression, only participants aged 12-19 years were selected for the study $(n=308)$. Of these, four were missing refractive error data, so were excluded from the study. Finally, 304 participants were found to be eligible (see Figure 1).

Baseline and clinical characteristics of participants, according to refractive status are reported in Table 1. Among the 304 eligible participants, 255 (84 per cent) were classified as myopic.

The characteristics of the myopic and non-myopic subjects are shown in Table 1. Apart from refraction, the only significant difference between the two groups was in BMI. Myopes were found to have a higher BMI $(21.5 \pm 0.2$ versus $19.8 \pm 0.6, p=0.02)$, but still within the normal range (18.5-24.9). There were no significant differences in age, gender, residence, parental income, height, and weight or waist circumference between myopes and non-myopes ( $p>0.05$ for all). Similarly, there was no significant difference between groups on self-reported level of recreational activity.

Mean serum zinc was slightly lower in the myopic group (138.1 \pm 2.3 versus $139.3 \pm 5.3, p=0.809$ ), but not statistically significantly so. Figure 2 shows the distribution and probability density of zinc level by myopia status as a violin plot. Each dot represents a participant. Table 2 presents the distribution of serum zinc by percentile, according to myopic status.

The association between serum zinc and myopia, in simple and multiple logistic regression models is presented in Table 3. The simple odds ratio (OR) with $95 \%$ confidence intervals $(\mathrm{Cl})$ indicated that serum zinc is not associated with risk of myopia. 


\begin{tabular}{|c|c|c|c|}
\hline & $\begin{array}{l}\text { Non-myopes } \\
\text { SE }>-0.50 \mathrm{D}\end{array}$ & $\begin{array}{c}\text { Myopes } \\
\text { SE }<=-0.50 \mathrm{D}\end{array}$ & p-value \\
\hline Number of subjects (\%) & $49(16 \%)$ & $255(84 \%)$ & \\
\hline \multicolumn{4}{|l|}{ Gender (\%) } \\
\hline Male & $28(57.1 \%)$ & $125(49.1 \%)$ & \\
\hline Female & $21(42.9 \%)$ & $130(50.9 \%)$ & 0.32 \\
\hline Age (years) & $15.4 \pm 0.4$ & $15.7 \pm 0.2$ & 0.56 \\
\hline \multicolumn{4}{|l|}{ Region (\%) } \\
\hline Urban & $38(77.5 \%)$ & $213(83.5 \%)$ & \\
\hline Rural & $11(22.5 \%)$ & $42(16.5 \%)$ & 0.88 \\
\hline \multicolumn{4}{|l|}{ Ocular exam } \\
\hline Spherical equivalent & $+0.37 \pm 0.2$ & $-3.30 \pm 0.2$ & $<0.001$ \\
\hline \multicolumn{4}{|l|}{ Systemic evaluation } \\
\hline Height (cm) & $1.65 \pm 1.6$ & $1.65 \pm 0.7$ & 0.94 \\
\hline Weight (kg) & $54.6 \pm 2.3$ & $58.8 \pm 0.9$ & 0.10 \\
\hline Body mass index (weight/height ${ }^{2}$ ) & $19.8 \pm 0.6$ & $21.5 \pm 0.2$ & 0.02 \\
\hline Waist $(\mathrm{cm})$ & $68.6 \pm 1.6$ & $71.4 \pm 0.7$ & 0.12 \\
\hline \multicolumn{4}{|l|}{ Recreational activity } \\
\hline Yes & $7(14.3 \%)$ & $60(23.5 \%)$ & \\
\hline No & $42(85.7 \%)$ & $195(76.5 \%)$ & 0.44 \\
\hline \multicolumn{4}{|l|}{ Low income (\%) } \\
\hline No & 38 (77.5\%) & $218(85.4 \%)$ & \\
\hline Yes & $11(22.5 \%)$ & 37 (14.5\%) & 0.42 \\
\hline Serum zinc ( $\mu \mathrm{g} / \mathrm{dl})$ & $139.3 \pm 5.3$ & $138.1 \pm 2.3$ & 0.81 \\
\hline
\end{tabular}

Table 1. Baseline and clinical characteristics of study participants

After adjustment for age and gender, the results were similar. Additional adjustments were made for BMI, residence, family income and recreational activity, in multivariate analysis. The multivariate adjusted ORs $(95 \% \mathrm{Cl})$ of myopia were $0.75(0.27-2.03$, ptrend $=0.66$ ) in the highest versus lowest quartile of serum zinc; no significant regression equation was found $(F=0.54, p=0.66)$.

The results of multiple linear regression for association between serum zinc and SE in the myopic group are shown in Table 4. The SE was not associated with serum zinc, in the simple model, or after adjustment for age and gender in model $1(p=0.52)$, and subsequent adjustment for $\mathrm{BMI}$, residence, family income, recreational activity in model $2(p=0.46)(F=0.56, p=0.46$, with an $\left.\mathrm{R}^{2}=0.057\right)$.

Sensitivity analyses were conducted to confirm the robustness of the results. Initially, all analyses were repeated using an alternative cut-off for myopia $(\leq-1.00 \mathrm{D})$, to account for lack of a cycloplegic agent during autorefraction. There was no significant difference between mean serum zinc in the myopic group ( $n=217$ ) compared to nonmyopes $(n=87) \quad(140.2 \pm 3.4$ versus $137.4 \pm 2.7, p=0.47)$. Similar to the above findings, no association was found between serum zinc and myopia after multiple logistic regression analysis $(p=0.61)$.

The analysis was also replicated for an older age group (20-39 years), to investigate the relationship further. Of the sample $(n=745)$, 185 were found to be non-myopic, while 560 were myopic. Again, there was no significant difference in mean serum zinc level $(p=0.89)$. The multiple logistic adjusted ORs $(95 \% \mathrm{Cl})$ of myopia were $1.43(0.818-2.526, \mathrm{p}$ trend $=0.86$ ) in the highest versus lowest quartile of serum zinc. The SE was not significantly associated with serum zinc after adjustment for confounders ( $p=0.98$ ).

\section{Discussion}

In this present study, we found no significant association between serum zinc and myopia in Korean adolescents aged 12-19, after adjustment for potential confounders. There were very few significant differences between the myopic and non-myopic subjects other than BMI which was marginally higher in the myopic adolescents - perhaps a reflection of a more sedentary lifestyle, or different dietary patterns. This study, which is perhaps one of the first to explore the association between serum zinc and myopia in adolescents using a subset of nationally representative data, revealed no association between serum zinc and refractive status.

These findings replicate the lack of association observed between myopia and dietary zinc status in a representative Western adolescent population, ${ }^{23}$ but are generally inconsistent with previous studies which have explored the relationship between serum zinc and myopia status. In a study of 121 children/adolescents, including 83 myopes and 38 controls, mean serum zinc was lower in myopes $(0.865 \pm 0.221 \mathrm{mg} / \mathrm{l})$ compared to controls $(1.054 \pm 0.174 \mathrm{mg} / \mathrm{l} ; \quad \mathrm{p}<0.001) .^{31} \quad$ Similar results were found in a study involving Chinese schoolchildren, where lower levels of serum zinc were found in myopic subjects $(0.98 \pm 0.21$ versus $1.5 \pm 0.23 \mathrm{mg} / \mathrm{l}$; $\mathrm{p}<0.05) .{ }^{15}$ Another study involving 220 primary school children in Dongguan district in China, again found significantly lower measures of serum zinc in myopes $(n=120)$, when compared to emmetropes $(n=100){ }^{14}$ This finding was backed-up by Huo et al. (males: $1.55 \pm 2.4$ versus $1.22 \pm 3.1 \mathrm{mg} / \mathrm{l}$; females: $1.48 \pm 2.4$ versus $1.21 \pm 2.7 \mathrm{mg} / \mathrm{l}$; $\mathrm{p}<0.01)$, and a negative correlation between serum zinc and degree of myopia was also reported. ${ }^{16}$

One possible explanation for the difference in findings may relate to methodological variation in serum zinc measurement and to reliability issues associated with the respective techniques. Previously published observational studies have all used an atomic absorption spectrometry technique, whereas, in our study, serum zinc was determined by ICP-MS. Both tools have their advantages, but it has been well documented that ICP-MS is a more sensitive technique, thus has better detection limits. ${ }^{32}$ Therefore, direct comparison between studies is difficult, and this may contribute to conflicting results. Retest reliability can also be poor in serum zinc testing. In a recent study, two different laboratories performed two subsequent serum zinc measurements in blinded duplicate of serum samples. The 


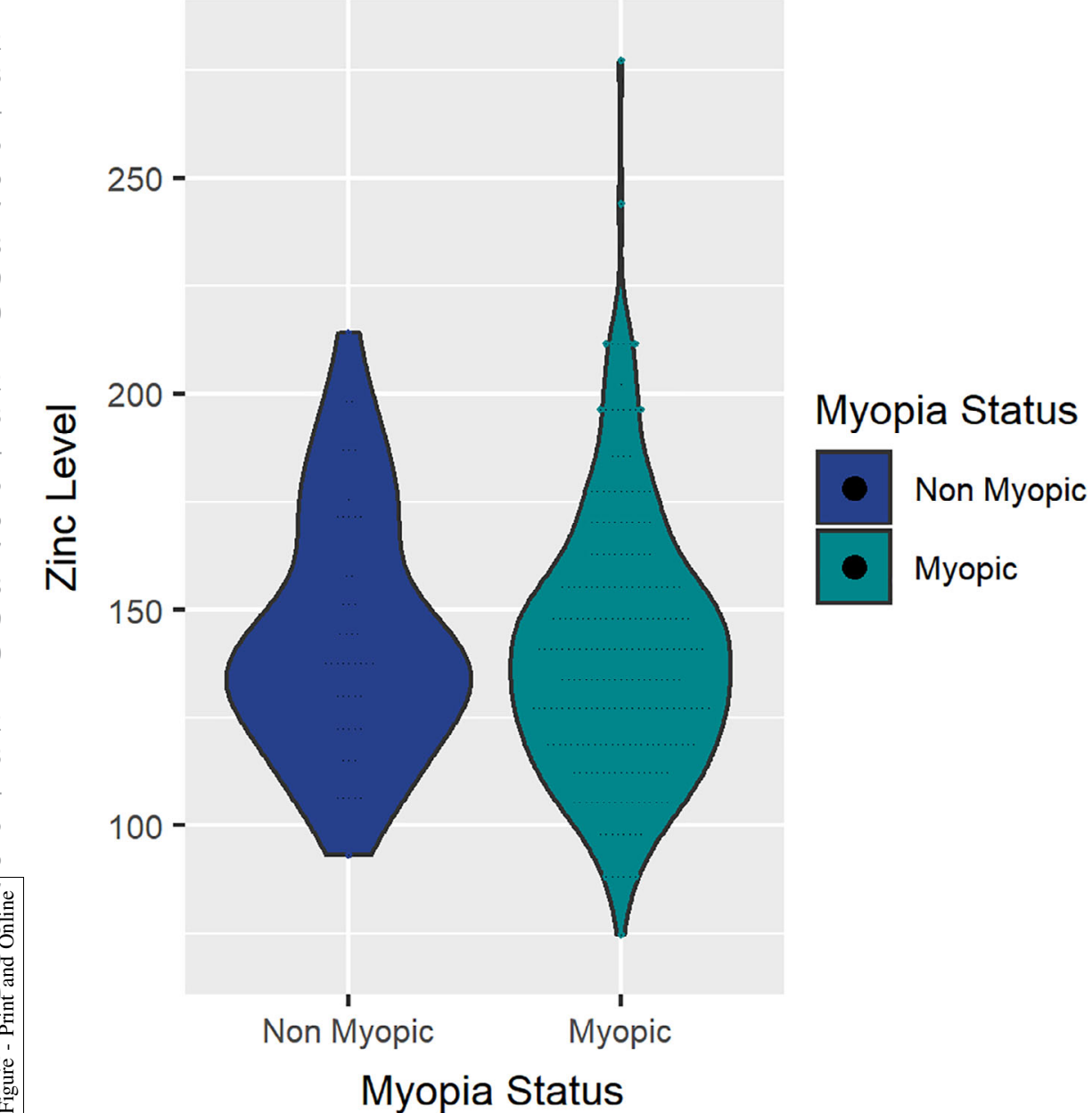

Figure 2. Violin plot of serum zinc concentration by myopic status.

commercial laboratory showed no significant correlation between both measured serum zinc concentrations $(r=0.21$; $p=0.44$ ), while the laboratory specialising in trace element research demonstrated a significant correlation of results from two subsequent measurements $(r=0.69 ; p<0.01)$. This only emphasises the difficulties in establishing zinc status, and the unreliability of measures. $^{33}$

Plasma zinc concentration is the most widely used biomarker to determine zinc status; however, measurements are the morning, after 12 hours fasting. Information regarding these specific processes are lacking in other published studies, ${ }^{15,31}$ leading to uncertainty around collection procedures. In addition to this, sample sizes are relatively small in current observational studies, therefore, data is unlikely to come from a diverse group - most studies include a sample of participants from the same school, most likely all from a similar geographical area, and socio-economic group. ${ }^{14,16}$ The interpretation of findings in relation to other studies is problematic, due to limitations such as homogenous data, certain confounders not adequately controlled and most importantly, differences in serum collection procedures and the overall difficulties in zinc measurement.

Micronutrient status is influenced by a plethora of factors. Differences in trace element concentration could result from soil, geographical location, food preparation, ethnic differences in body composition, genetics, cultural practices and even seasonal variation. ${ }^{35}$ In this study, all serum zinc measurements were found to be within the normal range, and mean serum zinc levels of participants was higher than in other study populations, as measured by the same or different methods. ${ }^{36,37}$ Previous studies have suggested that Koreans have a poorer zinc status when compared to Western countries. A study which looked at dietary zinc intake and serum zinc status of Koreans living in rural, urban and metropolitan areas of South Korea, reported zinc intakes lower than the Korean recommended daily allowance; it was also suggested that marginal zinc deficiency may be prevalent. ${ }^{38}$ However, interestingly, within each region plasma serum zinc measurements were within normal ranges $(70-150 \mathrm{mg} / \mathrm{l}) .^{38} \quad$ Another observational study examined the bioavailable zinc intake in 841 Korean adults; similar results were described, with below normative zinc intake in 62 per cent of males and 50 per cent of females. $^{20}$ These data demonstrate a discrepancy between dietary and serum zinc measures.

$\begin{array}{lcccccc} & \mathbf{n} & \text { Mean } & \text { Q1 (25th percentile) } & \text { Median (50th percentile) } & \text { Q3 (75th percentile) } & \text { p-value } \\ \text { Non-myope } & 49 & 139.3 & 116.5(100.7-132.3) & 136.2(127.3-145.1) & 154.6(135.6-173.6) & 0.81 \\ \text { Myope } & 255 & 138.1 & 117.8(112.5-123.1) & 133.6(128.8-138.5) & 152.5(147.2-157.7)\end{array}$

Table 2. Distribution of serum zinc by percentile in myopic and non-myopic Korean adolescents 


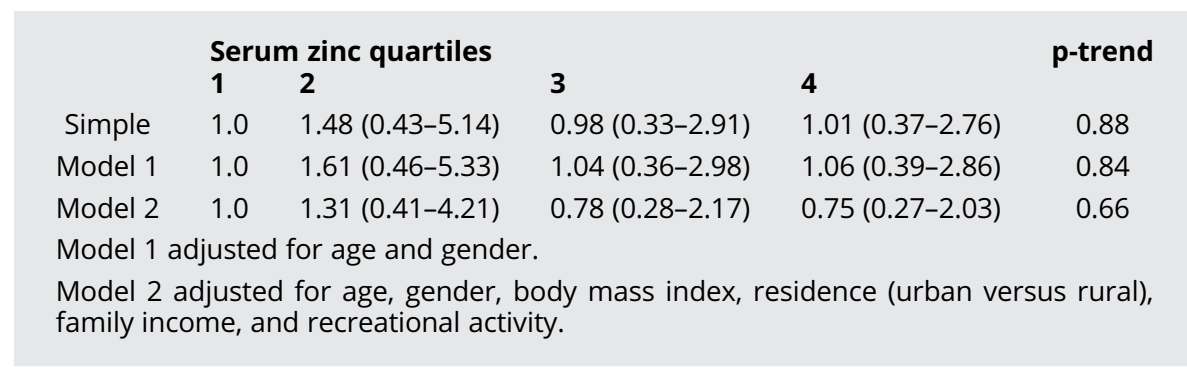

Table 3. Weighted odds ratio ( $95 \%$ confidence interval) for myopia across serum zinc level quartile

A potential dietary factor promoting marginal zinc deficiency in Koreans is high phytate and calcium intake, which decreases zinc absorption. In an analysis of Korean dietary patterns, cereals and grains were found to contribute most dietary zinc to the diet (48.9 per cent). Animal products, which contain the best sources of zinc, supplied 30 per cent of total zinc. The majority of rice, barley and legumes such as soy products. Rice alone contributed 54.1 per cent of total dietary phytate, making rice the major source of both zinc and phytate in the Korean diet. ${ }^{20}$ Phytate can bind zinc in the intestinal lumen and form an insoluble complex that cannot be digested or absorbed because humans lack the intestinal phytase enzyme. The negative effect of phytate on zinc absorption is dose-dependent. ${ }^{39}$ For this reason, plant-based diets are sometimes low in micronutrients, especially zinc. A systematic review of 34 studies compared males and females consuming vegetarian diets versus non-vegetarian diets; 26 studies were included in a meta-analysis, and dietary intake and serum zinc concentration phytate was supplied by cereals such as were found to be significantly lower in populations that consistently followed vegetarian compared to a non-vegetarian diets. ${ }^{40}$ Interestingly, a study carried out on young adults in India, found a higher prevalence of myopia among vegetarians than non-vegetarians; ${ }^{41}$ a separate UK study showed myopic children, treated with a high animal protein diet displayed slower progression of myopia, when compared to controls. ${ }^{11}$

The present study does have some limitations. All participants in this study were of Korean descent, it may be possible that serum zinc differs across different ethnic groups. The mean serum zinc level of myopic participants in this study was much higher when compared to other studies. Admittedly, the extent to which genetic factors influence an individual's serum zinc is unknown, but genetic polymorphisms that affect gene expression may alter zinc metabolism and homeostasis ${ }^{42}$ and therefore, findings in this study cannot be extrapolated to other populations.

The high prevalence of myopia among participants may have influenced results. The ratio of controls to cases is 0.2:1.0, far from the ideal in an epidemiology case/control study which is likely to be a consideration in all studies conducted in regions where myopia prevalence is high. Also, only one-third of the total examined group in KNHANES $V$ was chosen at random to give heavy metals blood samples, thus limiting sample size, and perhaps impacting the demographic diversity of the data sources. No cycloplegic was used during measurement of refractive status, therefore there may have been an overestimation of myopes, due to involuntary accommodation. However, a sensitivity analysis at more myopic thresholds did not change the results. Recreational activity was included in this study as a proxy for time spent outdoors; however, it is uncertain how true this measure is of UV light exposure, thus potential for residual confounding remains. In addition, axial length or corneal thickness were not measured and variables such as family history of myopia were not taken into consideration, and therefore again results may be confounded.

\section{Conclusion}

No significant association was found between serum zinc and myopia in a representative subsample of the Korean population in this age group. However, further well-designed prospective studies should be performed in a large cohort involving diverse ethnic groups, perhaps in less developed countries of South East Asia where zinc deficiency has been well documented. ${ }^{43}$ Furthermore, considering the vast limitations of serum zinc as a marker of zinc status, further resources should be devoted to
Table 4. Multiple linear regression analysis for the association between serum zinc and spherical equivalent in the myopic group (n = 255) 
the development of a better, more sensitive biomarkers of zinc status.

\section{ACKNOWLEDGEMENTS}

The authors thank the Korean National Health and Nutrition Examination Study for providing public access to its data.

\section{REFERENCES}

1. Holden BA, Fricke TR, Wilson DA et al. Global prevalence of myopia and high myopia and temporal trends from 2000 through 2050. Ophthalmology 2016; 123: 1036-1042.

2. Jung SK, Lee JH, Kakizaki $\mathrm{H}$ et al. Prevalence of myopia and its association with body stature and educational level in 19-year-old male conscripts in Seoul, South Korea. Invest Ophthalmol Vis Sci 2012; 53: 5579-5583.

3. Wong TY, Ferreira A, Hughes R et al. Epidemiology and disease burden of pathologic myopia and myopic choroidal neovascularization: an evidence-based systematic review. Am J Ophthalmol 2014; 157: 9-25.

4. Naidoo KS, Fricke TR, Frick KD et al. Potential lost productivity resulting from the global burden of myopia: systematic review, meta-analysis, and Modeling. Ophthalmology 2019; 126: 338-346.

5. Goldschmidt E, Jacobsen N. Genetic and environmental effects on myopia development and progression. Eye 2014; 28: 126-133.

6. Paritsis N, Sarafidou E, Koliopoulos J et al. Epidemiologic research on the role of studying and urban environment in the development of myopia during school-age years. Ann Ophthalmol 1983; 15: 1061-1065.

7. Rudnicka AR, Kapetanakis VV, Wathern AK et al. Global variations and time trends in the prevalence of childhood myopia, a systematic review and quantitative meta-analysis: implications for aetiology and early prevention. $\mathrm{Br} J$ Ophthalmol 2016; 100: 882-890.

8. Smith RG. Nutrition and eye diseases. J Orthomol Med 2010; 25: 67-76.

9. Chew EY. Nutrition effects on ocular diseases in the aging eye. Invest Ophthalmol Vis Sci 2013; 54: 42-47.

10. Lim LS, Gazzard G, Low YL et al. Dietary factors, myopia, and axial dimensions in children. Ophthalmology 2010; 117: 993-997.

11. Gardiner PA. Dietary treatment of myopia in children. Lancet 1958; 271: 1152-1155.

12. Edwards MH, Leung SSF, Lee WTK. Do variations in normal nutrition play a role in the development of myopia? Invest Ophthalmol Vis Sci 1996; 37: 638-643.
13. Cai Y. Determination of select trace elements in hair of college students in Jinzhou, China. Biol Trace Elem Res 2011; 144: 469-474.

14. Wang L. Variation analysis of six kinds of common micro- elements contents of blood in myopic primary school students in Dongguan district. Cent Chin Med 2009; 1: 20-21

15. Xie $\mathrm{X}, \mathrm{He} \mathrm{H}$, Wang J et al. Clinical significance of serum trace elements in juvenile patients with myopia. J Huaihai Med 2003; 4: 279-280.

16. Huo M, Liu HCJ. The relationship between serum zinc copper, selenium and the visions of middle schoo students. Chin J Sch Health 2006; 4: 318-319.

17. Juul F, Martinez-Steele $E$, Parekh $N$ et al. Ultraprocessed food consumption and excess weight among US adults. Br J Nutr 2018; 120: 90-100.

18. Jung $\mathrm{KY}$, Jung JH. Epidemiology of childhood injury in Korea. J Korean Med Assoc 2008; 51: 208-213.

19. Jung SJ, Kim MG, Park TS et al. Rice-based Korean meals (bibimbap and kimbap) have lower glycemic responses and postprandial-triglyceride effects than energy-matched Western meals. J Ethn Foods 2015; 2 154-161.

20. Joung $\mathrm{H}, \mathrm{Nam} \mathrm{G}$, Yoon $\mathrm{S}$ et al. Bioavailable zinc intake of Korean adults in relation to the phytate content of Korean foods. J Food Compos Anal 2004; 17: 713-724.

21. Christian P, West KP. Interactions between zinc and vitamin A: an update. Am J Clin Nutr 1998; 68: 435-441.

22. Young TL. Molecular genetics of human myopia: an update. Optom Vis Sci 2009; 86: 22

23. Burke N, Butler JS, Flitcroft I et al. Association of total zinc intake with myopia in US children and adolescents. Optom Vis Sci 2019; 96: 647-654.

24. Kiefer AK, Tung JY, Do CB et al. Genome-wide analysis points to roles for extracellular matrix remodeling the visual cycle, and neuronal development in myopia. PLoS Genet 2013; 9: 2

25. Jiang $D, L i ~ J, X i a o X$ et al. Detection of mutations in LAPAP1, CTSH, LEPREL1, ZN644, SLC39A5, and SCO2 in 298 families with early-onset high myopia by exome sequencing. Invest Ophthalmol Vis Sci 2015; 56: 339-345.

26. Korean Centers for Disease Control and Prevention Korea National Health and Nutrition Examination Survey. http://knhanes.cdc.go.kr.

27. Park HA. The Korea National Health and Nutrition Examination Survey as a primary data source. Korean J Fam Med 2013; 34: 79.

28. Choi JA, Han K, Park YM et al. Age-related Association of Refractive Error with intraocular pressure in the Korea National Health and nutrition examination survey. PLoS One 2014; 9. Available from. https://doi.org/ 10.1371/journal.pone.0111879.
29. Craig $C L$, Marshall $A L$, Sjöström $M$ et al. International Physical Activity Questionnaire: 12-country reliability and validity. Med Sci Sports Exerc 2003; 35: 12-1381.

30. Seo JA, Song SW, Han $K$ et al. The associations between serum zinc levels and metabolic syndrome in the Korean population: findings from the 2010 Korean national health and nutrition examination survey. PLoS One 2014; 9. Available from. https://doi.org/ 10.1371/journal.pone.0105990.

31. Fedor $M$, Socha $K$, Urban B et al. Serum concentration of zinc, copper, selenium, manganese, and $\mathrm{Cu} / \mathrm{Zn}$ ratio in children and adolescents with myopia. Bio Trace Elem Res 2017; 176: 1-9.

32. Tyler G. ICP-OES, ICP-MS and AAS techniques com pared. Technical note 05: ICP Optical Spectroscopy. 2001.

33. Trame $\mathrm{S}$, Wessels $\mathrm{I}$, Haase $\mathrm{H}$ et al. A short 18 items food frequency questionnaire biochemically validated to estimate zinc status in humans. I Trace Elem Med Biol 2018; 49: 285-295.

34. International Zinc Nutrition Consultative Group IZiNCG Technical Brief (Internet). IZiNCG. 2018. Available from: https://static1.squarespace.com/static/ $56424 \mathrm{f} 6 \mathrm{ce} 4 \mathrm{~b} 0552 \mathrm{eb} 7 \mathrm{fdc} 4 \mathrm{e} 8 / \mathrm{t} /$ 5c1abb0870a6adf8eb61d85b/1545255689912/ IZiNCG Technical+Brief+\%239 final.pdf

35. Choi R, Sun J, Yoo $\mathrm{H}$ et al. A prospective study of serum trace elements in healthy Korean pregnant women. Nutrients 2016; 8: 749.

36. Gonoodi K, Moslem A, Darroudi S et al Serum and dietary zinc and copper in Iranian girls. Clin Biochem 2018; 54: 25-31

37. Fan $Y$, Zhang C, Bu J. Relationship between selected serum metallic elements and obesity in children and adolescent in the U.S. Nutrients 2017; 9: 104.

38. Lee S-L, Kwak E-H, Yoon J-S et al. Zinc nutritional status in Korean adults from rural, Urban and metropolitan areas. Prev Nutr Food Sci 2010; 9: 174-182.

39. Roohani N, Hurrell R, Kelishadi R et al. Zinc and its importance for human health: an integrative review. J Res Med Sci 2013: 18: 144-157.

40. Foster M, Chu A, Petocz P et al. Effect of vegetarian diets on zinc status: a systematic review and metaanalysis of studies in humans. JSci Food Agric 2013; 93 2362-2371.

41. Sood RS. The prevalence of myopia Vis-à-Vis the type of diet in young adults. IJBAMS 2012; 2: 205-209.

42. Hess SY, Peerson JM, King JC et al. Use of serum zinc concentration as an indicator of population zinc status. Food Nutr Bull 2007; 28: S403-S429.

43. Wessells KR, Brown KH. Estimating the global prevalence of zinc deficiency: results based on zinc availability in National Food Supplies and the prevalence of stunting. PLoS One 2012; 7: e50568.
60 